\title{
Inhaltswerzeidhits.
}

Erbidaftiteuertarif ........... 8

\section{Tetl. Stenerpflifit.}

1. Begenftand ber Erbjfaftiteuer. $\$ \S 1$ bis $7 \ldots \ldots 9$

2. Perfönlidie Steuerpflidyt. $\$ \$ 8,9 \ldots \ldots \ldots \ldots$

3. Beredinung ber Steuer. $\S \S 10$ bis $13 \ldots \ldots \ldots$

4. Steuer $\{d u l d$ und Steueriduldorer. $\$ \$ 14$ bis $17 \ldots 25$

5. Befreiurgen und Ermäß̈igungen. $\$ \S 18$ bis $20 \ldots 30$

\section{Teil. BertermittIung.}

$\$ \$ 21$ bi $24 \ldots \ldots \ldots \ldots \ldots \ldots$

III. Teil. Beranlagung und Brhebung.

1. Steuerertlärung. $\$ \$ 25,26 \ldots \ldots \ldots \ldots \ldots$

2. Pflidten Dritter. $\$ \$ 27$ bis $29 \ldots \ldots$

3. Steutrejtfetzung. $\$ \$ 30$ bis $36 \ldots \ldots \ldots \ldots \ldots 1$

4. Stundung. $\$ \S 37$ bis $41 \ldots \ldots \ldots \ldots \ldots$

5. Eritattung. $\$ 42 \ldots \ldots \ldots \ldots \ldots \ldots$

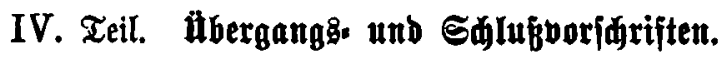

$\$ \$ 43,44 \ldots \ldots \ldots \ldots \ldots$

Sadregifter $\ldots \ldots \ldots \ldots \ldots_{\ldots . \ldots \ldots}$ 